\title{
Numerical Study to Evaluate the Performance of Non- uniform Stepped Spillway Using ANSYS-CFX
}

\author{
Shawnm M. Saleh ${ }^{1 *}$, Sarhang M. Husain² \\ ${ }^{1}$ Department of Water Resources, College of Engineering, Salahaddin University, Erbil, Kurdistan Region, Iraq, ${ }^{2}$ Department of Geomatics \\ (Surveying) Engineering, College of Engineering, Salahaddin University, Erbil, Kurdistan Region, Iraq
}

\section{*Corresponding author: \\ Shawnm M. Saleh, \\ Department of Water \\ Resources, College of \\ Engineering, Salahaddin \\ University, Erbil, Kurdistan \\ Region Iraq. \\ E-mail: shawnm.saleh@ \\ su.edu.krd}

Received: 12 March 2020

Accepted: 11 May 2020

Published: 30 December 2020

\section{DOI}

10.25156/ptj.v10n2y2020.pp1-9

\author{
A B S TR A C T
}

The main features that attract hydraulic engineers for designing stepped spillways are their ability to lose a large portion of the flow energy and add or increase aeration to the flow naturally. Hence, smaller size stilling basin and no aeration device may require. This study aims to find the amount of energy dissipation rate and the location of inception point over non-uniform stepped spillway. The numerical 2D ANSYS-CFX code is applied to generate and run thirty-two models of different configurations using two different moderate slopes $(1 \mathrm{~V}: 2 \mathrm{H}$ and $1 \mathrm{~V}: 2.5 \mathrm{H})$ as most of the downstream slopes designed for moderate slope, and two different step heights $\left(h_{s}=0.08 m\right.$ and $\left.h_{s}=0.016 m\right)$ under skimming flow discharge for different $\left(d_{c} / h_{s}\right)$ ranging from $d_{c} / h_{s}=1-2.2$, in which dc is the critical flow depth on the crest. The volume of fluid is implemented and the renormalized group of $k-\varepsilon$ turbulence model is activated. The computational results demonstrated that the amount of energy dissipation increases with decreasing the flow discharge, chute slope, and step height. In addition, it is observed that the length of the inception point is directly proportional to the discharge and inversely proportional to both the chute slopes and step height. Moreover, for the design point of view, the results revealed that configuration $\mathrm{B}$ can be considered as the optimal one amongst the others examined herein.

Keywords: ANSYS-CFX; Energy dissipation; Inception point; Non-uniform stepped spillway; Numerical simulation

\section{INTRODUCTION}

The stepped spillway considered as a powerful hydraulic structure for dissipating the overflowing energy because the steps behave like a macro-roughness (Boes and Hager, 2003). Several researchers found that this type of spillway can dissipate energy by two to three times greater than the traditional smooth spillway (Rajaratnam, 1990; Rice and Kadavy, 1996; Khalaf et al., 2014). Hence, no or smaller stilling basin is needed to decrease energy and that can greatly reduce the cost (Chanson, 1994). Step geometry, chute slope, step numbers, flow discharges, and flow regimes have an effect on the energy dissipation rate (Rad and Teimouri, 2010, Ahadian and Aghamajidi, 2014). In the skimming flow regime, the energy dissipation is due to both the aeration process and step geometry (Kavianpour and Masoumi, 2008).

The location of the self-aeration is essential for designing the training wall and to protect the spillway from the potential of cavitation risk (Hunt and Kadavy, 2009). This location is occurred on the chute slope as long as the developing turbulent boundary layer meets the water depth in a point that called inception point (Chanson, 2002). Upstream of this point, the water is smooth and may be vulnerable to cavitation damage. While, at the downstream, the existence of air is larger enough to protect the structure from scouring and can decrease the cost of aeration device (Van Alwon et al., 2017).

The amount of energy dissipation was predicted by many authors; for instance: (Rajaratnam, 1990) evaluated the energy dissipation for skimming flow with step height $0.15 \mathrm{~cm}$ for chute slope $1 \mathrm{~V}: 0.78 \mathrm{H}$ and proposed the following equation:

$$
E=\left(\frac{c_{f} q^{2}}{2 g \sin \theta}\right)^{1 / 3}+\left(\frac{q \sin \theta}{c_{f} \sqrt{2 g}}\right)^{2 / 3}
$$

Where $c_{f}$ is the skin friction coefficient $\left(c_{f} \approx 0.18\right), q$ is the flow discharge, and $g$ is the gravitational acceleration.

Moreover, (Tatewar and Ingle, 1996) analyzed the energy dissipation rate over stepped spillway as:

$$
\begin{aligned}
& \frac{\Delta E}{E}=0.000457 D-1.078\left(h_{s} / l_{s}\right) \\
& -1.99\left(d_{c} / H_{\text {dam }}\right)+2.339
\end{aligned}
$$


Where $D$ is the drop number and $D=\frac{q^{2}}{g h_{s}^{3}}, \Delta E$ is the energy loss, $E$ is energy at the crest of spillway, $h_{r}$ and $l_{r}$ are step height and step length respectively, $d$ is the critical depth, and $H_{\text {dam }}$ is the height of spillway.

At the upstream of the inception point, the following expression for the energy dissipation was developed by (Hunt and Kadavy, 2010) for chute slope $4 \mathrm{H}: 1 \mathrm{~V}$ and step height $38 \mathrm{~mm}$.

$$
\frac{\Delta E}{E_{0}}=0.3 \frac{L}{L_{i}}
$$

At which,

$E_{o}$ is the energy dissipation from downstream crest edge to the location of interest, $L$ is the length measured from crest of spillway, and $L_{i}$ length of inception point.

For upward inclined steps (Chinnarasri and Wongwises, 2004) evaluated the relative energy loss $\Delta E$ with respect to the head of the dam $H_{\text {dam }}$ for three different slopes and three-step inclinations $\alpha$ :

$$
\frac{\Delta E}{H_{\text {dam }}}=f_{2}\left[\frac{q^{2}}{g H_{\text {dam }}^{3}}, \frac{h_{s}}{l_{s}}, \alpha\right]
$$

Felder, 2013 determined the amount of energy loses over non-uniform stepped spillway for moderate slope as expressed in equation 5 . The same equation was used in this work to predict the amount of energy dissipation rate.

$$
\begin{aligned}
& \Delta H=H_{\text {max }}-H_{r e s} \\
& H_{\text {max }}=\Delta z_{\circ}+\frac{3}{2} * d_{c} \\
& H_{r e s}=d * \cos \theta+\frac{U_{w}^{2}}{2 * g}
\end{aligned}
$$

Where

$H_{\text {max }}$ is the maximum upstream head and $H_{\text {res }}$ is the residual head at the measured section, $\Delta_{\tau_{0}}$ is the height from the calculated step edge at the downstream end to the weir crest, and $d$ is equivalent clear water depth that described as:

$$
d=\int_{y=0}^{Y_{90}}(1-C) * d y
$$

$U_{w}$ is the flow velocity and expressed as:

$$
U_{w}=q / \int_{0}^{Y_{90}}(1-C) * d y
$$

Where, $C$ is air concentration, and $Y_{90}$ is the characteristic depth where $C=90 \%$.

According to Husain and AHMED, 2017, the energy dissipation rate reported as $89.1 \%$ on a physical model of uniformed stepped spillway of Bastora Dam.

Energy rate was found by Tabbara et al., 2005 over uniform horizontal steps using ADINA software. Chinnarasri et al., 2014 used FLUENT code in two dimensions to estimate the energy dissipation rate for moderate slope $1 \mathrm{~V}: 2 \mathrm{H}$ and number of steps $=25$.

$$
\frac{\Delta E}{E}=0.94 e^{-2.84\left(\frac{d_{c}}{i b_{s}}\right)}
$$

Where $i$ is index of step number.

Hamedi et al., 2012 studied the energy loss over inclined steps equipped with end sills using FLUENT 6.3. ANSYSCFX for 2D was used by Ahadian and Aghamajidi, 2014; Arora, 2017 to determine the energy dissipation over uniform stepped spillway. Their results show that the energy dissipation is decreased with increasing flow rate, number of steps, and chute slope. While, by increasing the step height, the value of energy dissipation increases.

ANSYS-CFX was also applied by Jalil and Hussein, 2017 over labyrinth and plain steps. According to their study, RNG k- $\varepsilon$ gives a better understanding of energy dissipation than the other models.

Location of inception point was found by many authors. To understand the effect of each chute slope and step height on the location of the inception point (Boes and Hager, 2003) used three different chute slopes with different step heights and obtained the following equation.

$$
L_{i}=\frac{5.9 d_{c}^{6 / 5}}{(\sin \theta)^{7 / 5} h_{s}^{1 / 5}}
$$

Where $F^{*}$ is the roughness Froude number.

Chanson, 1994 estimate the length of inception point for slope ranges from $27^{\circ}$ to $52^{\circ}$ as follows:

$$
\frac{L_{i}}{k_{s}}=9.8 *(\sin \theta)^{0.080} *\left(F_{*}\right)^{0.71}
$$

Where $k_{s}$ is the step height roughness and $k_{s}=h_{s} \cos \theta$

While, the above equation was modified by Hunt and Kadavy, 2009 so to be applied for $\theta<22^{\circ}$ and $F \star>10$ and they proposed the following equation: 


$$
\frac{L_{i}}{k_{s}}=6.10(\sin \theta)^{0.08}\left(F^{*}\right)^{0.86}
$$

Moreover, the length of inception point was derived by Felder and Chanson, 2009 for the chute slope of $21.8^{\circ}$ and expressed by:

$$
\frac{L_{i}}{h_{s} * \cos \theta}=1.05+5.11 * \frac{q}{\sqrt{g * \sin \theta *\left(h_{s} * \cos \theta\right)^{3}}}
$$

Zhang and Chanson, 2016 also worked on a uniform step spillway for the slope of $1 \mathrm{~V}: 1 \mathrm{H}$ and their results showed that the length of inception was increased with increasing the discharge.

The numerical code CFX has not been used for simulating the flow over stepped spillway with non-uniform step heights. This motivated us to use this code for determining the performance of the skimming flow regime over nonuniform stepped spillways.

The purpose of this work is to determine the amount of energy dissipation and location of inception point over non-uniform stepped spillway using 2D ANSYS-CFX code for moderate slopes $21.8^{\circ}$ and $26.6^{\circ}$ and different flow rates $\left(1 \leq d_{c} / h_{s} \leq 2.2\right)$

\section{STUDY TECHNIQUES}

In this work, the numerical code ANSYS-CFX code in two dimensions is applied to estimate the amount of energy dissipation rate and location of the inception point over non-uniform stepped spillway. The governing equation that introduced as Navier-Stokes equations can be expressed as:

Mass conservation

$$
\frac{\partial u}{\partial x}+\frac{\partial v}{\partial y}=0
$$

Momentum conservation

$$
\begin{aligned}
& \frac{\partial\left(\rho u_{i}\right)}{\partial t}+\frac{\partial}{\partial x_{j}}\left(\rho u_{i} u_{j}\right)=\rho g_{i}-\frac{\partial p}{\partial x_{i}}+\frac{\partial}{\partial x_{j}} \\
& \left\{\left(\mu+\mu_{t}\right)\left(\frac{\partial u_{i}}{\partial x_{j}}+\frac{\partial u_{j}}{\partial x_{i}}\right)\right\}
\end{aligned}
$$

Where $\rho=$ water density $\left(\mathrm{kg} / \mathrm{m}^{3}\right), \mu=$ kinetic viscosity of water $(\mathrm{kg} /(\mathrm{s} . \mathrm{m})), g=$ gravity acceleration $\left(\mathrm{m} / \mathrm{s}^{2}\right)$, $\frac{\partial p}{\partial x}=$ pressure differentiation $(\mathrm{Pa} / \mathrm{m}), \mu_{t}$ is the turbulent viscosity subscripts $J$ and $I$ refer to the $X$ and $Y$ directions, respectively.

\section{VALIDATION OF THE NUMERICAL CODE}

The laboratory results presented by Felder, 2013 were taken into consideration for validating the 2D ANSYSCFX in terms of both; first: The amount of energy lost at the last step of the spillway configuration and the location of inception point. This code has been recently validated by Saleh and Husain, 2019 using the same geometry and flow conditions and close agreements between the experimental and numerical data were obtained. The same software with the same numerical tools, grid size, and mesh type used by Saleh and Husain, 2019 are applied in the current study for estimating the energy dissipation rate and position of air-entrainment over non-uniform stepped spillways in different configurations.

\section{STEPS OF RUNNING}

1. Description of the configuration models: In total, thirty-two numerical models of stepped spillways are examined using eight configurations with various arrangements and two different slopes $(1 \mathrm{~V}: 2 \mathrm{H}$ and $1 \mathrm{~V}: 2.5 \mathrm{H})$. The height of the spillway is fixed to $1.28 \mathrm{~m}$ for all models with crest length $62 \mathrm{~cm}$ (the ration of crest length to the upstream head should be $>1.5$ [Chow, 1959]), as shown in Figures 1 and 2 with full details in Tables 1 and 2. These models are drawn by AUTOCAD software and then exported to the ANSYS workbench.

2. Gridding method: The same techniques implemented by Saleh and Husain, 2019 are applied herein for all configurations. The mesh size was set to $0.015 \mathrm{~m}$ and the hexahedral grid type was activated. Furthermore, the inflation tool supported by the numerical code is applied close to the walls in an attempt to increase the accuracy of the results.

3. Pre-processing: In the pre-processing, the boundary conditions are employed selected as follows:

a. Inlet: The inlet section treated as water inlet with the velocity inlet based on the discharge.

b. Outlet: Static pressure is applied for the outlet boundary section.

c. Opening: At the free-surface, the atmospheric pressure is adapted.

d. Walls: The walls selected as stationary and no-slip condition.

e. Symmetry: Symmetry was chosen for minimizing the running time.

4. Turbulence model: Following (Li and Zhang, 2018), the RNG k- $\varepsilon$ is used to introduce the effect of the 


\section{Configuration A}
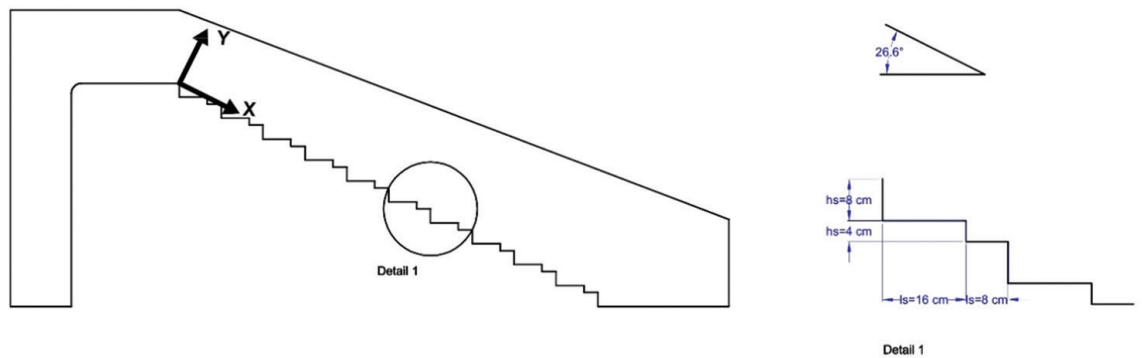

Configuration B
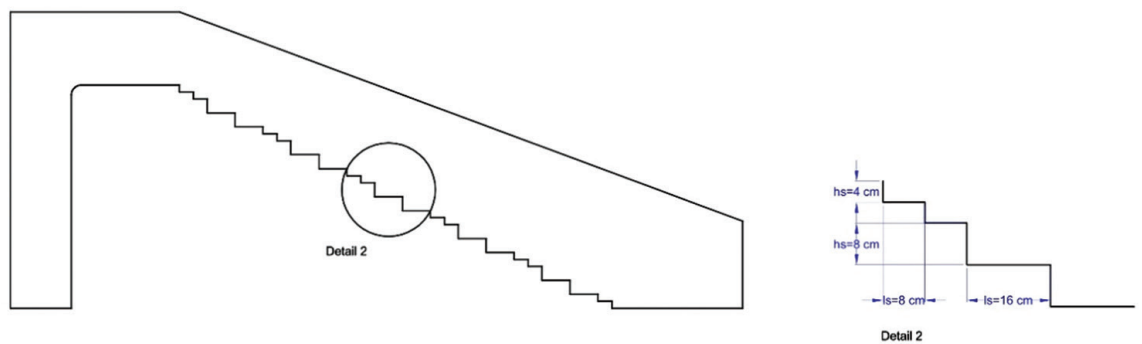

\section{Configuration $\mathrm{C}$}

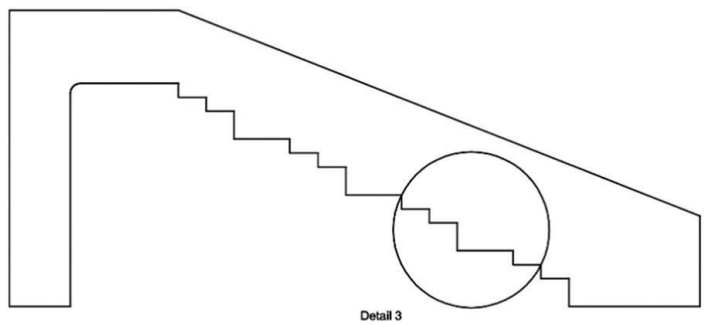

Configuration D
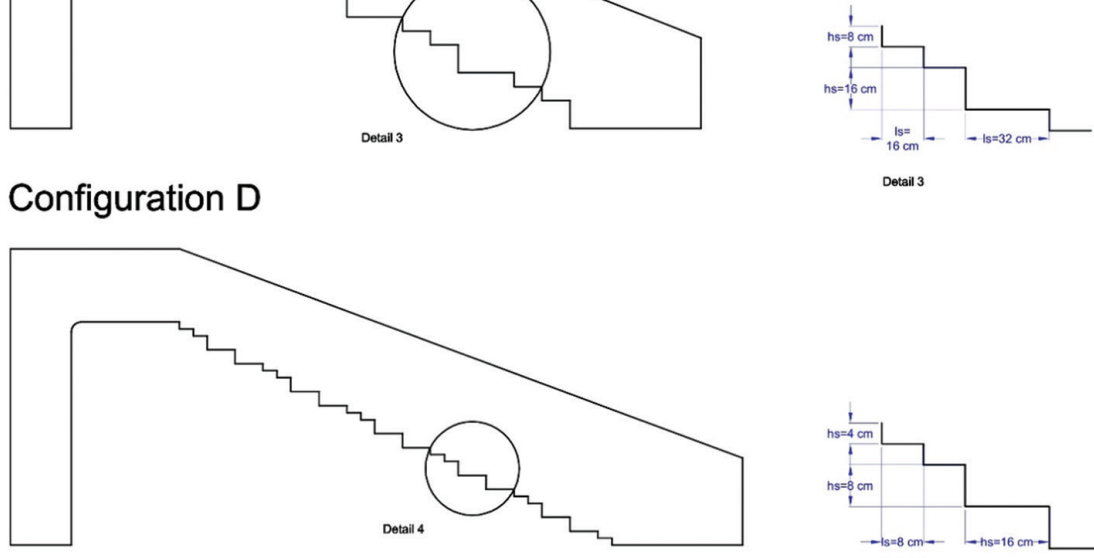

Detail

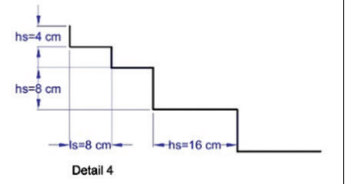

Figure 1: Step configurations for slope 1 V:2 H

turbulent structure as it provides more accurate numerical results.

5. Volume of fluid: Which is defined a powerful method for predicting the position of the interface between two or more immiscible fluids is selected.

\section{RESULTS AND DISCUSSION}

\section{Energy Dissipation}

As the amount of energy dissipation rate is high on stepped spillway, many researchers worked out to find the parameters effecting this amount. In this study, different parameters, including flow discharge, chute slope, and step heights, are examined to find their effect on the amount of energy losses. The computational results of energy dissipation $\left(\Delta \mathrm{H} / \mathrm{H}_{\max }\right)$ variation with the flow rate for all the thirty-two models are plotted in Figure 3. These data are also presented in Table 3.

As it appears in Figure 3 and Table 3, the discharge has a great effect on the amount of energy dissipation rate and it relates inversely to each other. The same observation was reported by Degoutte et al., 1992; Chafi et al., 2010; Guenther et al., 2013. 


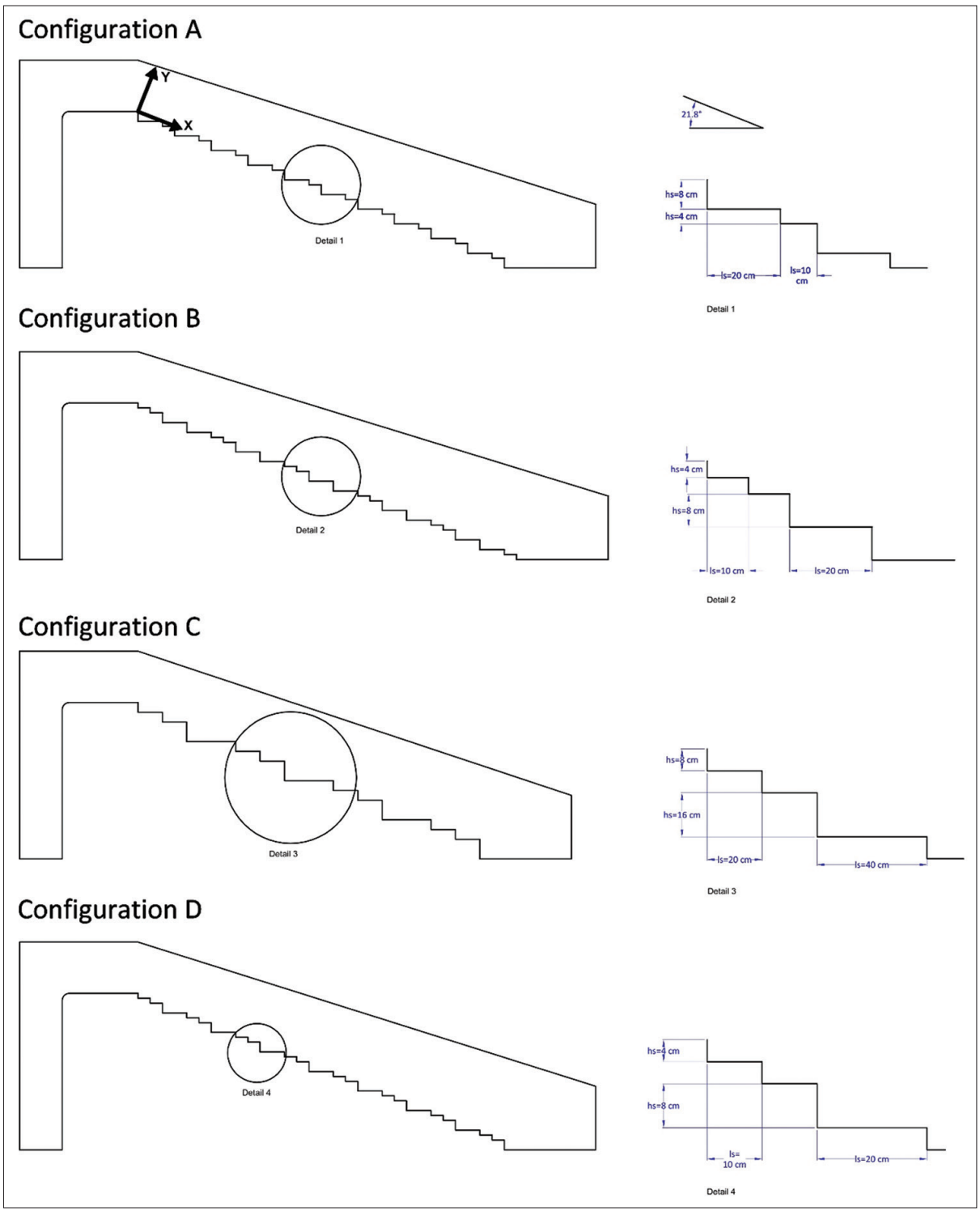

Figure 2: Step configurations for slope $1 \mathrm{~V}: 2.5 \mathrm{H}$

Table 1: Details of configurations for slope $26.6^{\circ}$ with $h_{s} / I_{s}=0.5$

\begin{tabular}{|c|c|c|c|c|c|}
\hline Configurations & $d_{c} / h_{s}[-]$ & $q\left(\mathrm{~m}^{2} / \mathrm{s}\right)$ & $\operatorname{Re}[-]$ & First layer height (m) & Number of step edges \\
\hline$A$ & 1 & 0.07087 & $3.2^{*} 10^{5}$ & 0.00026 & 21 \\
\hline \multirow{3}{*}{$\begin{array}{l}\text { Regular alternation of one step of } \mathrm{hs}=8 \mathrm{~cm} \\
\text { followed by one step of } \mathrm{hs}=4 \mathrm{~cm}\end{array}$} & 1.4 & 0.1174 & $5.3^{\star} 10^{5}$ & 0.000165 & \\
\hline & 1.8 & 0.17115 & $7.7^{*} 10^{5}$ & 0.00012 & \\
\hline & 2.2 & 0.2313 & $10.4^{*} 10^{5}$ & 0.00009 & \\
\hline B & 1 & 0.07087 & $3.2^{*} 10^{5}$ & 0.00026 & 22 \\
\hline \multirow{3}{*}{$\begin{array}{l}\text { Regular alternation of two steps of } h s=4 \mathrm{~cm} \\
\text { followed by two steps of } h s=8 \mathrm{~cm}\end{array}$} & 1.4 & 0.1174 & $5.3^{\star} 10^{5}$ & 0.000165 & \\
\hline & 1.8 & 0.17115 & $7.7^{*} 10^{5}$ & 0.00012 & \\
\hline & 2.2 & 0.2313 & $10.4^{*} 10^{5}$ & 0.00009 & \\
\hline C & 1 & 0.2 & $9 * 10^{5}$ & 0.0002 & 12 \\
\hline \multirow{3}{*}{$\begin{array}{l}\text { Regular alternation of two steps of } h s=8 \mathrm{~cm} \\
\text { followed by one step of } h s=16 \mathrm{~cm}\end{array}$} & 1.1 & 0.2312 & $10.4 * 10^{5}$ & 0.000177 & \\
\hline & 1.2 & 0.2635 & $11.8 * 10^{5}$ & 0.000157 & \\
\hline & 1.3 & 0.297 & $13.3^{*} 10^{5}$ & 0.00014 & \\
\hline D & 1 & 0.07087 & $3.2^{*} 10^{5}$ & 0.00026 & 24 \\
\hline \multirow{3}{*}{$\begin{array}{l}\text { Regular alternation of two steps of } h s=4 \mathrm{~cm} \\
\text { followed by one step of } h s=8 \mathrm{~cm}\end{array}$} & 1.4 & 0.1174 & $5.3^{*} 10^{5}$ & 0.000165 & \\
\hline & 1.8 & 0.17115 & $7.7^{\star} 10^{5}$ & 0.00012 & \\
\hline & 2.2 & 0.2313 & $10.4^{*} 10^{5}$ & 0.00009 & \\
\hline
\end{tabular}


Table 2: Details of configurations for slope $21.8^{\circ}$ with $h_{s} / I_{s}=0.4$

\begin{tabular}{|c|c|c|c|c|c|}
\hline Configurations & $d_{c} / h_{s}[-]$ & $Q\left(\mathrm{~m}^{2} / \mathrm{s}\right)$ & $\operatorname{Re}[-]$ & First layer height (m) & Number of step edges \\
\hline A & 1 & 0.07087 & $3.2^{*} 10^{5}$ & 0.00033 & 21 \\
\hline \multirow{3}{*}{$\begin{array}{l}\text { Regular alternation of one step of hs= } 8 \\
\mathrm{~cm} \text { followed by one step of } \mathrm{hs}=4 \mathrm{~cm}\end{array}$} & 1.4 & 0.1174 & $5.3^{*} 10^{5}$ & 0.000207 & \\
\hline & 1.8 & 0.17115 & $7.7^{*} 10^{5}$ & 0.000146 & \\
\hline & 2.2 & 0.2313 & $10.4^{*} 10^{5}$ & 0.00011 & \\
\hline B & 1 & 0.07087 & $3.2^{*} 10^{5}$ & 0.00033 & 22 \\
\hline \multirow{3}{*}{$\begin{array}{l}\text { Regular alternation of two steps of } \\
\mathrm{hs}=4 \mathrm{~cm} \text { followed by two steps of } \\
\mathrm{hs}=8 \mathrm{~cm}\end{array}$} & 1.4 & 0.1174 & $5.3^{*} 10^{5}$ & 0.000207 & \\
\hline & 1.8 & 0.17115 & $7.7^{*} 10^{5}$ & 0.000146 & \\
\hline & 2.2 & 0.2313 & $10.4^{*} 10^{5}$ & 0.00011 & \\
\hline C & 1 & 0.2 & $9 * 10^{5}$ & 0.00025 & 12 \\
\hline \multirow{3}{*}{$\begin{array}{l}\text { Regular alternation of two steps of } \\
\mathrm{hs}=8 \mathrm{~cm} \text { followed by one step of } \\
\mathrm{hs}=16 \mathrm{~cm}\end{array}$} & 1.1 & 0.2312 & $10.4^{*} 10^{5}$ & 0.00022 & \\
\hline & 1.2 & 0.2635 & $11.8^{*} 10^{5}$ & 0.000196 & \\
\hline & 1.3 & 0.297 & $13.3^{*} 10^{5}$ & 0.000176 & \\
\hline D & 1 & 0.07087 & $3.2^{*} 10^{5}$ & 0.00033 & 24 \\
\hline \multirow{3}{*}{$\begin{array}{l}\text { Regular alternation of two steps of } \\
\mathrm{hs}=4 \mathrm{~cm} \text { followed by one step of } \\
\mathrm{hs}=8 \mathrm{~cm}\end{array}$} & 1.4 & 0.1174 & $5.3^{*} 10^{5}$ & 0.000207 & \\
\hline & 1.8 & 0.17115 & $7.7^{*} 10^{5}$ & 0.000146 & \\
\hline & 2.2 & 0.2313 & $10.4^{*} 10^{5}$ & 0.00011 & \\
\hline
\end{tabular}

Table 3: Relative energy dissipation rate for different skimming flow regime discharges and for chute slopes $1 \mathrm{V:2} H$ and $1 \mathrm{~V}: 2.5 \mathrm{H}$ with different configurations of non-uniform stepped spillways

\begin{tabular}{|c|c|c|c|c|c|}
\hline \multicolumn{3}{|l|}{$1 \mathrm{~V}: 2 \mathrm{H}$} & \multicolumn{3}{|c|}{$1 \mathrm{~V}: 2.5 \mathrm{H}$} \\
\hline Configurations & $q\left(\mathrm{~m}^{2} / \mathrm{s}\right)$ & $\Delta \mathrm{H} / \mathrm{H} \max [-]$ & Configurations & $q\left(\mathrm{~m}^{2} / \mathrm{s}\right)$ & $\Delta \mathrm{H} / \mathrm{Hmax}[-]$ \\
\hline \multirow[t]{4}{*}{ A } & 0.07087 & 0.864 & A & 0.07087 & 0.852 \\
\hline & 0.1174 & 0.757 & & 0.1174 & 0.786 \\
\hline & 0.17115 & 0.612 & & 0.17115 & 0.674 \\
\hline & 0.2313 & 0.586 & & 0.2313 & 0.628 \\
\hline \multirow[t]{4}{*}{ B } & 0.07087 & 0.863 & B & 0.07087 & 0.861 \\
\hline & 0.1174 & 0.792 & & 0.1174 & 0.797 \\
\hline & 0.17115 & 0.691 & & 0.17115 & 0.714 \\
\hline & 0.2313 & 0.620 & & 0.2313 & 0.637 \\
\hline \multirow[t]{4}{*}{ C } & 0.2 & 0.560 & C & 0.2 & 0.613 \\
\hline & 0.2313 & 0.512 & & 0.2313 & 0.570 \\
\hline & 0.2635 & 0.507 & & 0.2635 & 0.569 \\
\hline & 0.297 & 0.504 & & 0.297 & 0.541 \\
\hline \multirow[t]{4}{*}{ D } & 0.07087 & 0.854 & D & 0.07087 & 0.853 \\
\hline & 0.1174 & 0.776 & & 0.1174 & 0.782 \\
\hline & 0.17115 & 0.603 & & 0.17115 & 0.673 \\
\hline & 0.2313 & 0.532 & & 0.2313 & 0.610 \\
\hline
\end{tabular}

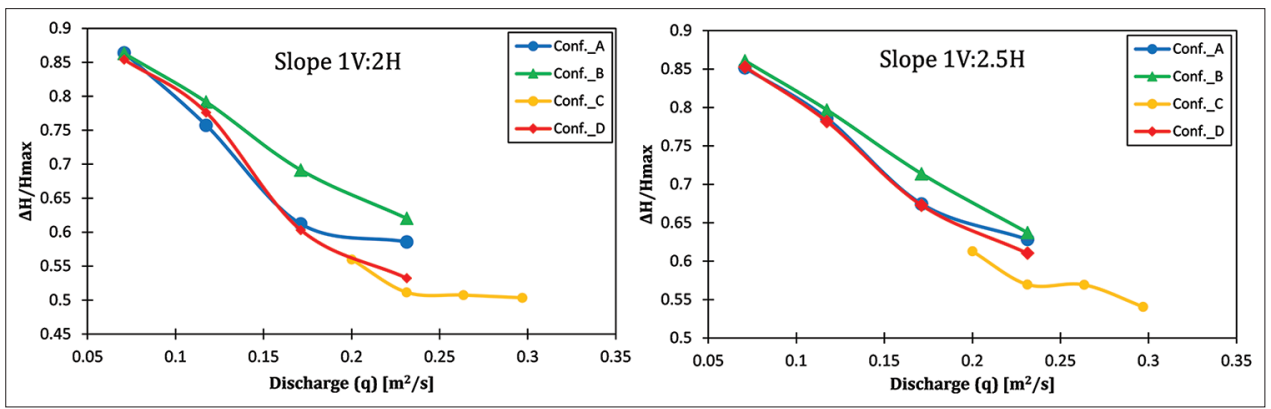

Figure 3: Energy dissipation rate in non-uniform stepped spillways versus skimming flow regime discharge for chute slopes $1 \mathrm{~V}: 2 \mathrm{H}$ and $1 \mathrm{~V}: 2.5 \mathrm{H}$ and different configurations of non-uniform stepped spillways

However, it can be observed that with decreasing the chute slope, the value of relative energy loss is increased, as can be noted in Figure 3. This also agrees with what documented (Degoutte et al., 1992; Rad and Teimouri, 2010). It is worth mentioning here that the amount of energy that is dissipated by model configurations A, B, and D for both chute slopes are nearly the same. This can be attributed to the fact that at small discharges of the skimming flow regime, the flow behavior is close to that of the transition flow regime. 
Moreover, the effect of the number of steps on energy dissipation is obvious from the data tabulated in Table 3. Although configurations $\mathrm{C}$ and $\mathrm{D}$ both have the same arrangement, with different step height (step number), a larger amount of energy dissipated is obtained when the number of steps is increased for the same flow discharges. This is because, as mentioned earlier, the steps along the downstream slope act as roughness elements, and with increasing the number of steps, the friction is increased. The effect of the number of steps on the amount of energy dissipation was investigated by Christodoulou, 1993; Chamani, 1998; Rad and Teimouri, 2010; Attarian et al., 2014 and they pointed out to the same finding.

Furthermore, it is obvious that model configuration B performs better in terms of dissipation the overflowing energy compared with other configurations examined in this work as it produces higher amount of energy dissipation than the others for almost all of the discharges, with the difference in step arrangements.

\section{Inception Point}

The length of the inception point is essential to be determined because upstream of that point may subject to cavitation damage and also used for designing the side walls. Following (Chanson, 2002), the location of the inception point in the current work is estimated to be the point on the chute slope at which the thickness of the developing turbulent boundary layer intersect the free surface. Figures 4 and 5 show that how the thickness of the turbulent boundary layer $(\boldsymbol{\delta})$ is developed along the chute slopes measured form the end of the crest length for
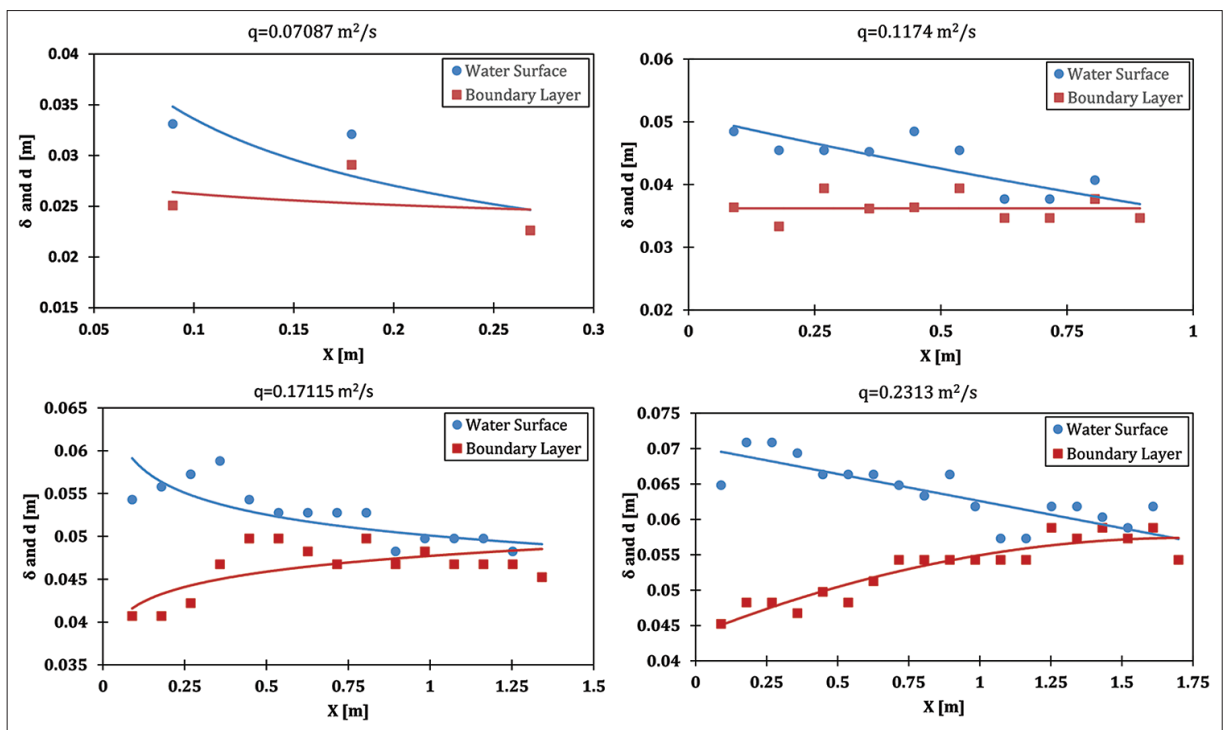

Figure 4: Length of the inception point for configuration A on the chute slope $1 \mathrm{~V}: 2 \mathrm{H}$
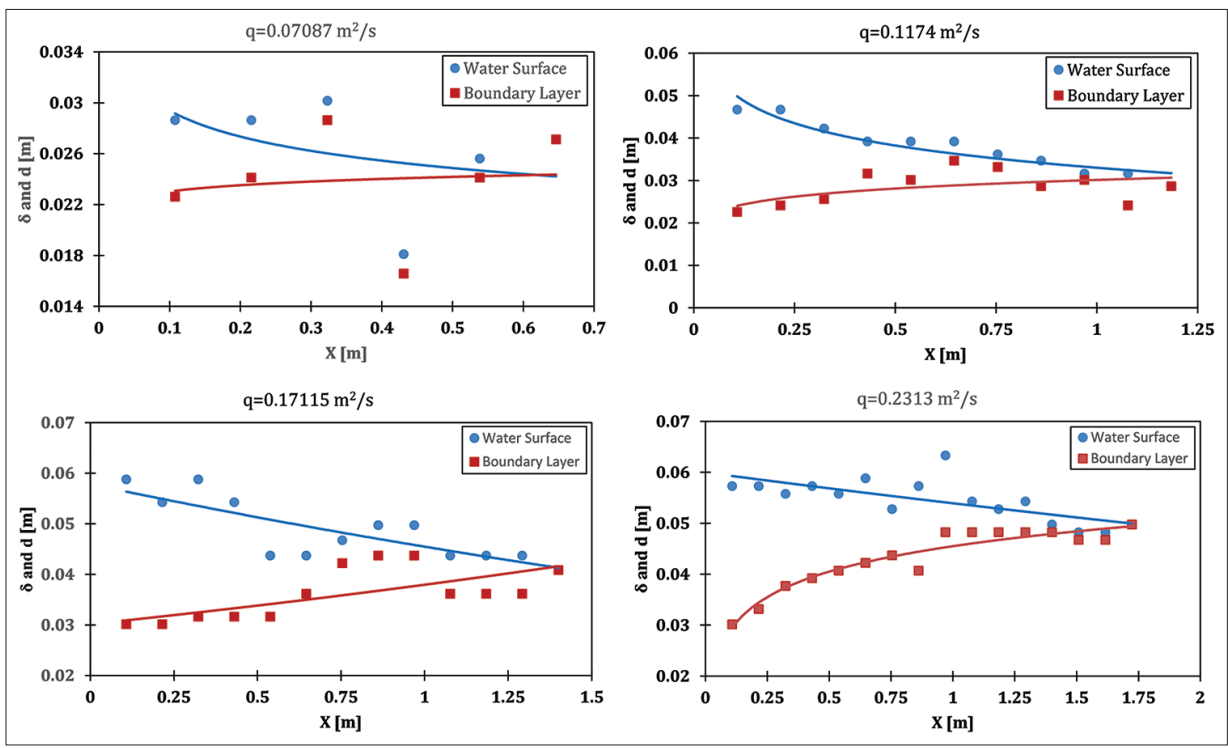

Figure 5: Length of inception point for configuration A on the chute slope $1 \mathrm{~V}: 2.5 \mathrm{H}$ 


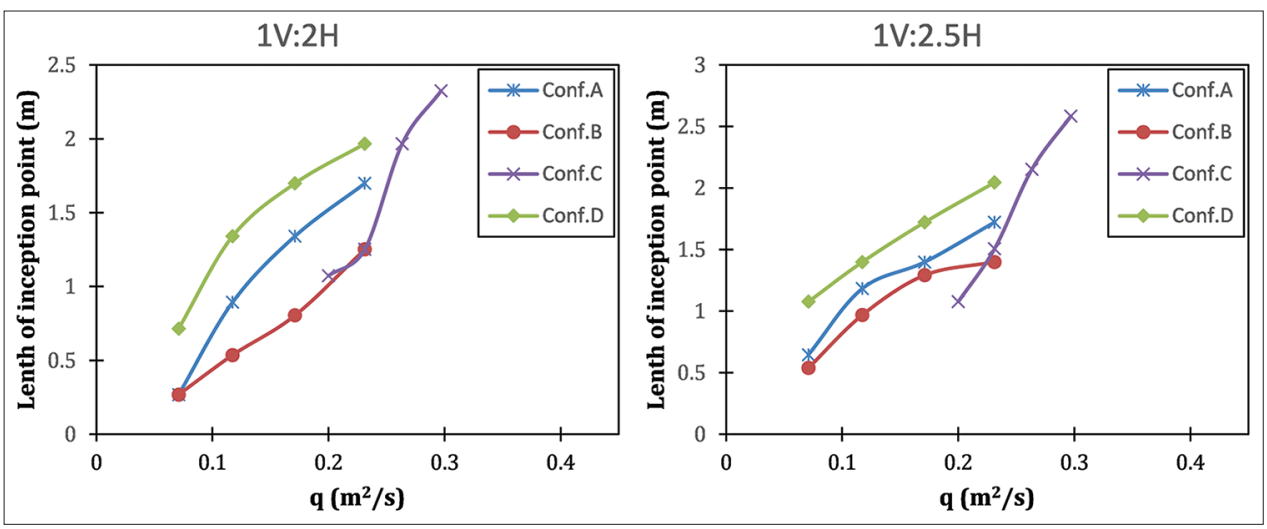

Figure 6: Location of inception point versus unit discharge for all configurations and chute slopes

Table 4: Length and depth of inception point for different discharges and chute slopes

\begin{tabular}{|c|c|c|c|c|c|c|c|}
\hline \multicolumn{5}{|l|}{ Slope $1 \mathrm{~V}: 2 \mathrm{H}$} & \multicolumn{3}{|c|}{ Slope 1 V:2.5 H } \\
\hline Configurations & $q\left(m^{2} / s\right)$ & $\mathrm{Li}$ & di & $\begin{array}{l}\text { Inception point in } \\
\text { which step edge }\end{array}$ & Li & di & $\begin{array}{l}\text { Inception point in } \\
\text { which step edge }\end{array}$ \\
\hline \multirow[t]{4}{*}{ A } & 0.07087 & 0.268326 & 0.0226 & 3 & 0.646218 & 0.0271 & 5 \\
\hline & 0.1174 & 0.894427 & 0.0347 & $7-8$ & 1.184733 & 0.0286 & 8 \\
\hline & 0.17115 & 1.341641 & 0.0452 & 11 & 1.400139 & 0.0408 & $9-10$ \\
\hline & 0.2313 & 1.699411 & 0.0543 & $13-14$ & 1.723248 & 0.0498 & $11-12$ \\
\hline \multirow[t]{4}{*}{ B } & 0.07087 & 0.268326 & 0.0241 & $3-4$ & 0.538515 & 0.0211 & $4-5$ \\
\hline & 0.1174 & 0.536656 & 0.0407 & 5 & 0.969327 & 0.0241 & $7-8$ \\
\hline & 0.17115 & 0.804984 & 0.0513 & $7-8$ & 1.292436 & 0.0362 & 9 \\
\hline & 0.2313 & 1.252198 & 0.0633 & 11 & 1.400139 & 0.0558 & 10 \\
\hline \multirow[t]{4}{*}{ C } & 0.2 & 1.07331 & 0.0407 & 6 & 1.077035 & 0.0588 & 5 \\
\hline & 0.2313 & 1.252195 & 0.0467 & $6-7$ & 1.507849 & 0.0378 & $6-7$ \\
\hline & 0.2635 & 1.967735 & 0.0573 & $9-10$ & 2.15407 & 0.0588 & 9 \\
\hline & 0.297 & 2.325505 & 0.0543 & 11 & 2.584884 & 0.0527 & 10 \\
\hline \multirow[t]{4}{*}{ D } & 0.07087 & 0.715542 & 0.0211 & 7 & 1.07703 & 0.0256 & 9 \\
\hline & 0.1174 & 1.341641 & 0.0347 & $12-13$ & 1.400139 & 0.0347 & 11 \\
\hline & 0.17115 & 1.699411 & 0.0407 & $15-16$ & 1.723248 & 0.0362 & 13 \\
\hline & 0.2313 & 1.967737 & 0.0543 & 18 & 2.046357 & 0.0452 & 15 \\
\hline
\end{tabular}

configuration A and chute slopes $1 \mathrm{~V}: 2 \mathrm{H}$ and $1 \mathrm{~V}: 2.5 \mathrm{H}$, respectively, for the range of discharges tested in the current work. The boundary layer thickness shows almost constant for the first two discharges in steeper slope; this is because, for the mentioned slope, the disturbance of the turbulent layer is higher. In these figures, the corresponding water surface profiles are also drawn.

The same procedure is used for all the other configurations to predict the position of inception point and the results are depicted in Figure 6 and Table 4. These results point out that for the same discharge, the length to the inception point is generally longer on the flatter slopes. The same result was documented by Boes and Hager, 2003; Husain, 2013. In addition, as it can be observed, the point of inception moves downward as the flow rate is increased. This can be justified on the fact that by increasing the discharge, the water depth increases, and hence, longer distance is required for the boundary layer to grow and reach the free surface. Chamani, 1998; Husain, 2013; Munta and Otun, 2014 made the same observation. Finally, as it is clear from Table 4, configuration B provides a shorter length to the inception point compared to configurations A and D for all flow discharges and both slopes. This could help the designers of such structures to select this kind of model configuration to avoid the potential of occurring cavitation phenomenon.

\section{CONCLUSION}

In this work, the amount of energy dissipation and the location of inception point over non-uniform stepped spillway are estimated numerically using the twodimensional ANSYS-CFX code. To do so, thirty-two models having two moderate slopes $1 \mathrm{~V}: 2 \mathrm{H}$ and $1 \mathrm{~V}: 2.5 \mathrm{H}$ and four different discharges with a range of $d_{c} / h_{s}$ between 1 and 2.2 are examined. Based on the numerical results, it can be concluded that the amount of energy loss increases 
with decreasing the flow rate and reducing the chute slope. However, the dissipation rate increases as the number of steps increase because of increasing surface roughness. Furthermore, it is found that for the same flow discharge and chute slope, the model configuration $\mathrm{B}$ provides a higher amount of energy dissipation rate. Furthermore, the length of inception point goes upward with increasing the spillway slope. In addition, with increasing the flow discharge, the length of inception point is increased too as the boundary layer needs a longer distance to meet the water depth. One more conclusion to be mentioned is that configuration B is optimal for designing non-uniform stepped spillways to run under the skimming flow regime. This is because it performs much better than the other configurations examined in this work in reducing the cavitation risk as it provides the shortest distance of inception point. More research is needed to be conducted to evaluate the performance of these configurations under the nappe and transition flow regimes.

\section{REFERENCES}

Ahadian, J. and R. Aghamajidi. 2014. Investigation of geometric effect of steps on energy dissipation on stepped spillway. Appl. Math. Eng. Manag. Technol. 2: 491-503.

Arora, C. 2017. Analysis of flow over a stepped spillway using ansys fluent. Imperial J. Interdiscip. Res. 3: 297-302.

Attarian, A., K. Hosseini, H. Abdi and M. Hosseini. 2014. The effect of the step height on energy dissipation in stepped spillways using numerical simulation. Arab. J. Sci. Eng. 39: 2587-2594.

Boes, R. M. and W. H. Hager. 2003. Two-phase flow characteristics of stepped spillways. J. Hydraul. Eng. 129: 661-670.

Chafi, C., A. Hazzab and A. Seddini. 2010. Study of flow and energy dissipation in stepped spillways. Jordan J. Civil Eng. 4: 1-11.

Chamani, M. R. 1998. Skimming flow in a large model of a stepped spillway. J. Hydraul. Eng. 135: 47.

Chanson, H. 1994. Hydraulics of skimming flows over stepped channels and spillways. J. Hydraul. Res. 32: 445-460.

Chanson, H. 2002. Hydraulics of Stepped Chutes and Spillways. CRC Press, Boca Raton, Florida, United States.

Chinnarasri, C. and S. Wongwises. 2004. Flow regimes and energy loss on chutes with upward inclined steps. Can. J. Civil Eng. 31: 870-879.

Chinnarasri, C., D. Kositgittiwong and P. Y. Julien. 2014. Model of Flow Over Spillways by Computational Fluid Dynamics. In: Proceedings of the Institution of Civil Engineers-Water Management. Thomas Telford Ltd., London, England. p164-175.

Chow, V. T. 1959. Open-Channel Hydraulics. McGrow-Hill, New York.

Christodoulou, G. C. 1993. Energy dissipation on stepped spillways. J. Hydraul. Eng. 119: 644-650.

Degoutte, G., L. Peyras and P. Royet. 1992. Discussion of "skimming flow in stepped spillways" by N. Rajaratnam (April, 1990, Vol. 116, No. 4). J. Hydraul. Eng. 118: 111-113.

Felder, S. 2013. Air-water Flow Properties on Stepped Spillways for Embankment Dams: Aeration, Energy Dissipation and Turbulence on Uniform, Non-uniform and Pooled Stepped Chutes. Phd. Thesis.
Felder, S. and H. Chanson. 2009. Turbulence, dynamic similarity and scale effects in high-velocity free-surface flows above a stepped chute. Exp. Fluids. 47: 1-18.

Guenther, P., S. Felder and H. Chanson. 2013. Flow aeration, cavity processes and energy dissipation on flat and pooled stepped spillways for embankments. Environ. Fluid Mech. 13: 503-525.

Hamedi, A., I. Malekmohammadi, A. Mansoori and H. Roshanaei. 2012. Energy Dissipation in Stepped Spillway Equipped with Inclined Steps Together with End Sill. In: $4^{\text {th }}$ International Conference on Computational Intelligence and Communication Networks. IEEE, Piscataway, New Jersey. p638-642.

Hunt, S. L. and K. C. Kadavy. 2009. Inception Point Relationship for Flat-sloped Stepped Spillways, 2009 Reno, Nevada, June 21June 24, 2009. American Society of Agricultural and Biological Engineers, St. Joseph, Michigan, United States.

Hunt, S. L. and K. C. Kadavy. 2010. Energy dissipation on flat-sloped stepped spillways: Part 1. Upstream of the inception point. Trans. ASABE. 53: 103-109.

Husain, S. M. 2013. Computational Investigation of Skimming Flow on Stepped Spillways Using the Smoothed Particle Hydrodynamics Method. Swansea University, United Kingdom.

Husain, S. M. and S. S. Ahmed. 2017. Experimental study to evaluate the hydraulic performance of Bastora dam stepped spillway. J. Duhok Univ. 20: 612-625.

Jalil, S. A. and B. S. Hussein. 2017. Experimental and modelling of flow over labyrinth and plain stepped falls. J. Duhok Univ. 10: 662-679.

Kavianpour, M. R. and H. R. Masoumi. 2008. New approach for estimating of energy dissipation over stepped spillways. Int. J. Civil Eng. 6: 230-237.

Khalaf, R. M., R. H. Irzooki and S. J. Shareef. 2014. Flow Characteristics and Energy Dissipation Over Traditional and Stepped Spillway with Semicircular Crest, Project.

Li, S. and J. Zhang. 2018. Numerical investigation on the hydraulic properties of the skimming flow over pooled stepped spillway. Water. 10: 1478.

Munta, S. and J. Otun. 2014. Study of the inception length of flow over stepped spillway models. Niger. J. Technol. 33: 176-183.

Rad, I. N. and M. Teimouri. 2010. An investigation of flow energy dissipation in simple stepped spillways by numerical model. Eur. J. Sci. Res. 47: 544-553.

Rajaratnam, N. 1990. Skimming flow in stepped spillways. J. Hydraul. Eng. 116: 587-591.

Rice, C. E. and K. C. Kadavy. 1996. Model study of a roller compacted concrete stepped spillway. J. Hydraul. Eng. 122: 292-297.

Saleh, S. M. and S. M. Husain. 2019. Validation of the computational ANSYS-CFX code for free surface flow: Skimming flow over non-uniform step size stepped spillways. ZANCO J. Pure Appl. Sci. 31: 361-367.

Tabbara, M., J. Chatila and R. Awwad. 2005. Computational simulation of flow over stepped spillways. Comput. Struct. 83: 2215-2224.

Tatewar, S. P. and R. N. Ingle. 1996. Energy dissipation in skimming flow over stepped spillways. ISH J. Hydraul. Eng. 2: 45-51.

Van Alwon, J., D. Borman, A. Sleigh and N. Kapur. 2017. Experimental and Numerical Modelling of Aerated Flows Over Stepped Spillways. In: Proceedings of IAHR 2017. International Association for Hydro-Environment Engineering and Research.

Zhang, G. and H. Chanson. 2016. Hydraulics of the developing flow region of stepped spillways. I: Physical modeling and boundary layer development. J. Hydraul. Eng. 142: 04016015. 